\title{
PENGARUH PENERAPAN POLA KOMUNIKASI ORGANISASI TERHADAP KINERJA PEGAWAI PADA PUSAT PENGEMBANGAN DAN PEMBERDAYAAN PENDIDIK DAN TENAGA KEPENDIDIKAN (P4TK) BISNIS \& PARIWISATA JAKARTA
}

\author{
Nani Nuraini Sarah ${ }^{1}$ \\ Dosen Prodi D-III Sekretari Universitas Pamulang \\ Nani20.sarah@gmail.com \\ Waluyo ${ }^{2}$ \\ Dosen Prodi D-III Sekretari Universitas Pamulang \\ waluyop4tkbispar@gmail.com
}

\begin{abstract}
ABSTRAK-Tujuan dari mempelajari Ilmu komunikasi adalah untuk mengembangkan dan meningkatkan kemampuan berkomunikasi dengan sesama manusia, sehingga dapat saling berkomunikasi dengan lebih efektif dalam mencapai tujuan, baik tujuan individu, tujuan organisasi maupun tujuan masyarakat. Di dalam Komunikasi Organisasi ada Budaya Komunikasi dengan garis hubungan yang berbeda. Garis hubungan vertikal kebawah, yaitu antara atasan dan bawahan, garis hubungan horizontal yaitu komunikasi antar pegawai dan garis hubungan yang terakhir adalah vertikal keatas dari pegawai ke atasannya. Tiap garis hubungan tersebut ada polanya masing-masing. Jika pola komunikasi berjalan tidak mengikuti aturannya, maka pelaksanaan komunikasi akan berjalan kurang baik. Pelaksanaan komunikasi yang efektif sangat penting untuk dapat mendorong semangat serta meningkatkan kinerja pegawai. Pelanggaran komunikasi seringkali disebabkan karena pelaku tidak mengetahui bahwa komunikasi mereka telah melanggar jalur ketertiban. Maksud dari penelitian ini adalah untuk memperoleh gambaran yang mendalam dan memberikan bukti empiris mengenai pengaruh pola komunikasi organisasi terhadap kinerja pegawai. Penelitian yang dilakukan menggunakan metode penelitian kuantitatif atau sering juga disebut sebagai metode tradisional. Yaitu dimana data yang dihasilkan akan berupa angka-angka dan analisisnya menggunakan statistik. Hasil pengujian regresi menunjukkan bahwa variabel pola komunikasi organisasi mempengaruhi kinerja pegawai di Pusat Pengembangan dan Pembedayaan Pendidik dan Tenaga Kependidikan (P4TK) Bisnis dan Pariwisata Jakarta.
\end{abstract}

\section{Kata kunci: Komunikasi, Pola komunikasi, kinerja pegawai}

ABSTRACT-The main purpose of studying communication is to develop and improve the ability to communicate with humans, so they can interact with each other more effectively in achieving goals, both individual goals, organizational goals and community goals. In the context of organizational communication, an organizational culture sees communication relationships from the perpetrator's relationship line. The downward vertical relationship line, that is between superiors and subordinates, the horizontal relationship line is between one employee and another employee and last one is upward vertical relationship line, that is between the employee to the superior. Each of these lines of communication has its own pattern. If the communication pattern does not go according 
to the rules, then the implementation of communication will not work well. This will become one of the disturbances or obstacles in achieving company performance because the message is not conveyed correctly. Communication violations that occur are mostly caused by the perpetrators of the communication not knowing that they have violated the order lines. The purpose of this study is to obtain an in-depth picture and provide empirical evidence regarding the effect of organizational communication patterns on employee performance. The research used quantitative research methods or often referred to as traditional methods. The resulting data will be in the form of numbers and the analysis uses statistics. The results of regression testing show that the variable organizational communication patterns affect the performance of employees at Pusat Pengembangan dan Pemberdayaan Pendidik dan Tenaga Kependidikan (P4TK) Bisnis dan Pariwisata Jakarta.

Keywords: Communication, communication patterns, employee performance

\section{PENDAHULUAN}

Aktivitas komunikasi dalam organisasi hampir selalu sejalan dengan tujuan yang dikehendaki anggota kelompok atau masyarakat. Di dalam Komunikasi Organisasi ada Budaya Komunikasi yang dapat dipandang dari 3-sisi yang berbeda. Komunikasi atasan ke bawahannya adalah sisi yang pertama. Selanjutnya adalah komunikasi antar pegawai. Dan sisi yang terakhir (ketiga) adalah komunikasi pegawai kepada atasannya. Tiap-tiap komunikasi tersebut ada polanya masingmasing.

Komunikasi dianggap penting dalam suatu organisasi, karena organisasi merupakan sekelompok manusia yagn saling bergantung dalam bkerja untuk mencapai beberapa tujuan. Dengan melakukan komunikasi, anggota kelompok bekerja dan saling berhubungan. Selain itu komunikasi adalah sarana yang efektif bagi anggota kelompok untuk berkoordinasi serta menjadi sarana untuk menyatakan harapan-harapan mereka kedepan.

Rencana-rencana, instruksi-instruksi, petunjuk serta saran dapat terganggu dan mengakibatkan kacaunya pekerjaan apabila pelaksanaan komunikasi tidak berjalan baik. Pelanggaran yang terjadi sering diakibatkan oleh pelaku yang tidak menyadari bahwa komunikasinya ada diluar jalur ketertiban. Oleh sebab itu pelaksanaan komunikasi yang efektif sangat penting untuk dapat mendorong semangat serta meningkatkan kinerja pegawai. Harapannya adalah dengan kinerja yang baik akan memudahkan organisasi/perusahaan mencapai tujuannya.

Pola komunikasi adalah suatu aturan penyampaian pesan dari komunikator kepada komunikan denagn tujuan agar dapat merubah sikap, atau perilaku atau pendapat komunikan tersebut. Aturan penyampaian berdasarkan penggunaan teori- 
teori komunikasi baik itu berupa pesan langsung atau pesan yang menggunakan media. Pesan-pesan komunikasi dapat berupa simbol-simbol bahasa non-verbal maupun bahasa verbal, melalui berbagai media/saluran komunikasi seperti komputer, audio visual, majalah, buletin ataupun surat kabar.

Pola komunikasi berhubungan erat dengan kinerja. Sedangkan Kinerja adalah suatu bentuk usaha yang menghasilkan tujuan organisasi, rasa puas konsumen, serta memberi kontribusi nilai ekonomi. Kinerja bersifat individual, dan tiap karyawan berbeda kemampuannya dalam mengerjakan tugas yang diberikan. Kinerja adalah suatu sikap mental yang beranggapan bahwa harus selalu ada perbaikan setiap harinya dalam menjalani kehidupan. Sikap ini dipandang dapat menahan seseorang agar tidak cepat puas, sehingga ia akan selalu berusaha meningkatkan kemampuan dirinya serta melakukan perbaikan kerja serta mencari cara untuk mengembangkan dirinya.

Jadi, apabila aturan pola komunikasi dilanggar, maka pesan tidak dapat tersampaikan dengan baik, dan ini berarti telah terjadi hambatan/gangguan untuk mencapai kinerja yang maksimal. Perbedaan bahasa dalam suatu organisasi dapat menghambat komunikasi yang selanjutnya berdampak kepada kinerja pegawai.
Fakta dilapangan menunjukkan bahwa kinerja pegawai tidak maksimal, ditambah lagi dengn masih adanya pegawai yang kurang memiliki pengetahuan tentang sistem kediklatan, kurang disiplin terhadap jam kerja, pegawai yang kurang mandiri/ tidak komit pada tugas dan tanggung-jawabnya sehingga perlu peningkatan integritas dalam sistem kerjanya.

$$
\text { Jajaran }
$$

fungsional Pusat

Pengembangan dan Pemberdayaan Pendidik dan Tenaga Kependidikan (P4TK) telah melaksanakan sejumlah usaha terkait penerapan pola komunikasi bagi para pegawai, akan tetapi sejauh ini perubahan kinerja pegawai dirasakan belum signifikan. Kinerja pegawai P4TK Bisns dan Pariwisata dalm melayani dan mengelola Diklat seyogyanya harus diberikan perhatian lebih, karena hal ini menyangkut keberadaan dan kepercayaan P4TK Bisnis dan Pariwisata yang diberi tugas pemerintah sebagai lembaga Diklat pemerintah.

Tuntutan masyarakat terhadap pemerintah sangat tinggi, terutama dalam manajemen kerja dan dalam hal memberi perhatian serta memberi pelayanan masyarakat. Kenyataan yang ditemui menunjukkan belum optimalnya pegawai P4TK Bisnis \& Pariwisata dalam memberikan pelayanan kepada peserta Diklat. Dari hasil survei peneliti di lapangan, ditemui hal-hal sebagai berikut: kurangnya 
persiapan dan adanya keterlambatan distribusi bahan ajar, Sering terjadi perubahan schedule ketika pelatihan sedang berlangsung, instruktur/ widyaiswara yang terlambat datang, penentuan peserta Diklat yang tidak sesuai dengan kebutuhan, pemanggilan peserta dan instruktur/widyaiswara yang singkat/mendadak.

Masalah-masalahdiatas sesungguhnya tidak akan muncul andaikata pegawai yang terlibat di dalam pengelolaan Diklat mengikuti pola komunikasi yang terstruktur. Tujuan organisasi akan mudah tercapai apabila kinerja pegawai tampil prima. Demikian sebaliknya juga bila kinerja pegawai berkurang, maka akan membuat pekerjaan tidak kunjung selesai dan terasa membosankan.

Melihat pentingnya kaitan pola komunikasi dengan kinerja pegawai, maka tujuan penelitian adalah untuk melihat:

1. Bagaimana penerapan pola komunikasi organisasi pada P4TK"Bisnis dan Pariwisata Jakarta?

2. Bagaimana kinerja pegawai P4TK Bisnis dan Pariwisata Jakarta?

3. Apakah ada pengaruh pola komunikasi terhadap kinerja pegawai pada P4TK Bisnis dan Pariwisata Jakarta?

Sedangkan Wibowo (2014:241) menulis, "Komunikasi merupakan proses penyampaian informasi dari satu pihak baik

\section{TEORI \& METODE PENELITIAN}

\section{Komunikasi}

Komunikasi menempati posisi penting dalam kehidupan manusia sehingga membuat ilmu komunikasi terus-menerus dikembangkan dan dipelajari dalam upaya mengembangkan kemampuan berkomunikasi antar manusia sehingga mereka dapat berkomunikasi secara efektif demi untuk mencapai tujuan.

Dalam bukunya Rachmat, J (2008:1), jelas-jelas mengatakan, “ Komunikasi merupakan suatu proses sosial yang sangat mendasar dan vital dalam kehidupan manusia". Dianggap sangat mendasar karena setiap manusia, apakah itu dalam kelompok masyarakat primitif ataupun masyarakat modern, pasti berusaha mempertahankan berbagai kesepakatan sosial dengan cara berkomunikasi. Dan disebut vital, karena adanya kemampuan tiap individu itu untuk saling berkomunikasi.

individu, kelompok atau organisasi sebagai sender kepada pihak lain sebagai receiver untuk memahami dan membuka peluang untuk memberi respon balik kepada sender".

\section{Pola Komunikasi}

"Pola komunikasi adalah suatu gambaran yang sederhana dari proses komunikasi yang memperlihatkan kaitan antara satu komponen komunikasi dengan komponen lainnya", demikian disampaikan 
Soejanto (2005:27). Selanjutnya Anhar (2010:31) mengutip dari Bahri sebagai berikut, "Pola komunikasi adalah suatu bentuk pola hubungan antara dua orang atau lebih dalam melakukan proses pengiriman dan penerimaan pesan dengan cara yang tepat dan efektif sehingga pesan yang akan ditujukan dapat dipahami”.

Kinerja pegawai dipengaruhi oleh Pola komunikasi organisasi . Efektivitas pola komunikasi organisasi akan mendorong peningkatan kinerja pegawai. Hal ini sesuai dengan penelitian yang dilakukan oleh Dede (2012) yang menemukan bahwa dengan adanya pola komunikasi yang efektif akan dapat meningkatkan kinerja pegawai khususnya pada Dinas Pendidikan Propinsi Jawa Barat.

"Kinerja merupakan perilaku nyata yang ditampilkan setiap orang sebagai prestasi kerja yang dihasilkan oleh pegawai sesuai dengan perannya dalam organisasi”. (Rivai dan Sagala, 2008:36). "Kinerja adalah suatu tampilan keadaan secara utuh atas perusahaan selama periode waktu tertentu, merupakan hasil atau prestasi yang dipengaruhi oleh kegiatan operasional organisasi dalam memanfaatkan sumbersumber yang dimiliki". Selanjutnya Rivai dan Sagala memberikan 6 (enam) kriteria utama yang digunakan untuk melihat sejauh mana kinerja pegawai diterapkan, yaitu:

1. Kualitas Kerja
2. Kuantitas Kerja

3. Ketepatan Waktu

4. Efektivita Kerja/Biaya

5. Pengawasan/Supervisi

6. Dampak Interpersonal

Dalam suatu organisasi, Kinerja Pegawai menjadi sebuah faktor penentu bagi berkembangnya organisasi tersebut. Itulah sebabnya Kinerja Pegwai menjadi hal yang teramat penting bagi organisasi dalam mencapai tujuannya.

\section{Pengelompokkan Komunikasi}

Menurut Puffery dalam Pratminingsih (2006:12), pengelompokkan komunikasi terbagi antara Komunikasi Informal dan Komunikasi Formal. Dalam organisasi, tentu akan dilihat pada Komunikasi Formalnya. "Ditinjau dari arahnya, Komunikasi Formal dapat dikelompokkan menjadi 3 (tiga), yaitu:

1. Komunikasi ke bawah (downward communication)

Komunikasi ke bawah merupakan komunikasi yang terjadi antara seseorang dengan bawahannya dalam suatu organisasi. Adapun bentuknya bisa berupa memo, kebijaksanaan, perintah, presentasi, rapat, majalah perusahaan, buletin dan sebagainya.

2. Komunikasi ke atas (upward communication)

Komunikasi ke atas merupakan komunikasi dari bawahan ke atasan, dan 
biasanya dalam laporan, baik tertulis maupun tidak.

3. Komunikasi sejajar/horizontal (lateral communication)

Komunikasi sejajar merupakan komunikasi di antara orang-orang yang mempunyai jabatan yang selevel tapi berbeda departemen.

\section{Kerangka Berpikir}

Kerangka berpikir dari penelitian ini digambarkan dalam kerangka dibawah ini :

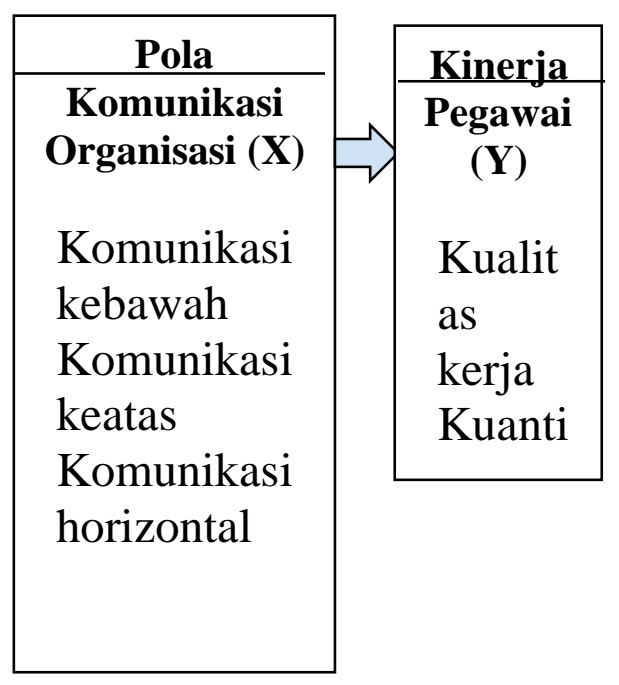

Sumber : Bernandin dan Russel (2008:82) Rivai dan Sagala, (2005:35)

\section{Metode Penelitian}

Metode Tradisional atau yang dikenal sebagai metode penelitian kuantitatif dipilih untuk penelitian ini, karena dianggap lebih simple namun tetap akurat. Data yang dihasilkan akan muncul berupa angka- angka yang kemudian dianalisa dengan menggunakan statistik.
Data diambil dari kuesioner berstruktur atau kuesioner tertutup. Penyusunan kuesioner didasarkan pada indikator dari ketiga variable penelitian dan dijabarkan setiap itemnya. Selanjutnya pemberian angka hasil kuesioner, menggunakan skala Likert.

Penulis menggunakan metode analisis statistik agar dapat mengetahui pengaruh Penerapan Pola Komunikasi (X) terhadap Kinerja Pegawai (Y) pada Pusat Pengembangan dan Pemberdayaan Pendidik dan Tenaga Kependidikan (P4TK) Bisnis dan Pariwisata Jakarta.

Setelah berhasil melalui Uji Validitas dan Uji Reliabilitas, maka dilakukan Uji Hipotesis untuk melihat seberapa besar pengaruh penerapan pola komunikasi terhadap kinerja pegawai. Adapun rumus regresi liner sederhana adalah: $\mathbf{Y}=\mathbf{a}+\mathbf{b X}$

\section{HASIL PEMBAHASAN}

Deskripsi kategori variabel menggambarkan tanggapan responden atas adanya pengaruh penerapan pola komunikasi terhadap kinerja pegawai pada P4TK Bisnis dan Parwisata Jakarta. Hasil kategorisasi indikator disajikan dalam tabel berikut: 
1. Variabel Komunikasi dari Atas (Vertikal Kebawah)

\begin{tabular}{|c|c|c|c|}
\hline $\begin{array}{c}\text { Katego } \\
\text { ri }\end{array}$ & $\begin{array}{c}\text { Interval } \\
\text { Skor }\end{array}$ & Freq. & $(\%)$ \\
\hline Tinggi & $X \geq 32,269$ & 7 & $14 \%$ \\
\hline Sedang & $\begin{array}{r}26,251 \leq X \\
<32,269\end{array}$ & 34 & $68 \%$ \\
\hline $\begin{array}{l}\text { Renda } \\
\mathrm{h}\end{array}$ & $X<26,251$ & 9 & $18 \%$ \\
\hline \multicolumn{2}{|l|}{ Total } & & $\begin{array}{l}100 \\
\%\end{array}$ \\
\hline
\end{tabular}

Data diambil th. 2019

Pola Komunikasi dengan Indikator Komunikasi dari Atas Kebawah mayoritas dinilai dalam kategori sedang (68\%).

2. Variable Komunikasi dari Bawah (Vertikal Keatas)

\begin{tabular}{|l|l|l|l|}
\hline $\begin{array}{l}\text { Kateg } \\
\text { ori }\end{array}$ & $\begin{array}{l}\text { Interval } \\
\text { Skor }\end{array}$ & Freq. & $(\%)$ \\
\hline Tinggi & $\mathrm{X} \geq 27,341$ & 7 & $14 \%$ \\
\hline Sedang & $\begin{array}{r}21,339 \leq \mathrm{X}< \\
27,341\end{array}$ & 35 & $70 \%$ \\
\hline $\begin{array}{l}\text { Renda } \\
\text { h }\end{array}$ & $\mathrm{X}<21,339$ & 8 & $16 \%$ \\
\hline Total & & & $\begin{array}{l}100 \\
\%\end{array}$ \\
\hline
\end{tabular}

Data diambil th. 2019

Penilaian mayoritas $70 \%$ termasuk kategori sedang untuk Pola Komunikasi dari Bawah Keatas.

3. Variabel Komunikasi Horizontal

\begin{tabular}{|l|c|c|c|}
\hline $\begin{array}{c}\text { Katego } \\
\text { ri }\end{array}$ & $\begin{array}{c}\text { Interval } \\
\text { Skor }\end{array}$ & Freq. & $(\%)$ \\
\hline Tinggi & $\mathrm{X} \geq 14,453$ & 7 & $14 \%$ \\
\hline Sedang & $\begin{array}{r}11,307 \leq X \\
<14,453\end{array}$ & 34 & $68 \%$ \\
\hline $\begin{array}{l}\text { Renda } \\
\text { h }\end{array}$ & $\mathrm{X}<11,307$ & 9 & $18 \%$ \\
\hline Total & & 50 & $\begin{array}{c}100 \\
\%\end{array}$ \\
\hline
\end{tabular}

Data diambil th. 2019
Penilaian mayoritas $68 \%$ termasuk kategori sedang untuk Pola Komunikasi Horizontal.

4. Variabel Kinerja Pegawai

\begin{tabular}{|c|c|c|c|}
\hline Kateg & Interval & Freq. & $(\%)$ \\
\hline Tingoj & $X>59.19$ & 1 & \\
\hline HIISET & $4881<\mathrm{X}<$ & & $2 \%$ \\
\hline Sedang & 59,19 & 9 & $18 \%$ \\
\hline $\begin{array}{l}\text { Renda } \\
h\end{array}$ & $X<48,81$ & 40 & $80 \%$ \\
\hline \multicolumn{2}{|l|}{ Total } & & $\begin{array}{c}100 \\
\%\end{array}$ \\
\hline
\end{tabular}

Data diambil th. 2019

Kinerja Pegawai mayoritas $80 \%$ termasuk kategori rendah untuk Kinerja Pegawai.

Hasil dari Uji Koefisien Determinasi diketahui bahwa kontribusi pengaruh penerapan pola komunikasi sebesar $48,9 \%$ terhadap kinerja pegawai pada P4TK Bisnis dan Parwisata Jakarta. Sedangkan sisanya sebesar $51,1 \%$ kemungkinan disebabkan karena adanya variabel lain yang tidak diteliti.

Dari Hasil Uji t (parsial) didapat bahwa variable penerapan pola komunikasi berpengaruh positif terhadap kinerja pegawai pada P4TK Bisnis dan Pariwisata Jakarta. Artinya jika nilai pola komunikasi bertambah, maka kenerja pegawai juga bertambah dengan signifikan

Dari Analisis korelasi Product Moment didapat 0.699 sebagai nilai koefisien korelasi. Untuk itu bisa dinyatakan adanya 
korelasi yang erat antara Pola Komunikasi (X) dengna Kinerja Pegawai (Y) di P4TK Bisnis dan Pariwisata Jakarta.

\section{PENUTUP}

\section{Kesimpulan}

Kesimpulan yang dapat ditarik adalah:

1. Hasil pengolahan data regresi menunjukkan adanya pengaruh yang signifikan antara Pola Komunikasi Organisasi (terdiri dari pola vertikal kebawah, vertikal keatas, dan horizontal) terhadap Kinerja Pegawai di P4TK Bisnis danPariwisata. Apabila komunikasi organisasi yang dimiliki pegawai baik, maka tingkat kinerja pegawai juga akan semakin baik. Sebaliknya, bila pegawai tersebut tidak/kurang mampu berkomunikasi organisasi, maka akan terlihat rendah tingkat kinerjanya.

2. Hasil Deskriptif menunjukkan bahwa 1 responden $(2 \%)$ memberikan penilaian variabel kinerja pegawai dalam kategori tinggi, 9 responden (18\%) cenderung pada kategori sedang dan sebanyak 40 responden $(80 \%)$ cenderung memberi penilaian pada kategori rendah. Kinerja pegawai mayoritas dinilai dalam kategori rendah $(80 \%)$.

3. Dari hasil pengujian regresi, terbukti ada nilai beta dan adanya nilai $\mathrm{t}$ tabel yang lebih kecil dari nilai t hitung; selain itu terlihat juga mempunyai nilai sig yang lebih kecil. Artinya variable pola komunikasi organisasi cenderung berpengaruh terhadap kinerja pegawai di P4TK Bisnis dan Pariwsata.

\section{DAFTAR PUSTAKA}

\section{$\underline{\text { Sumber Buku }}$}

Alwi, Syafaruddin (2008), Manajemen Sumber Daya Manusia, edisi kedua, cetakan pertama, Yogyakarta: BPFE

Anhar, Ahmad (2010), Pola Komunikasi Kepemimpinan Becak Wisata Dalam Membangun Kohesivitas Anggota. Diakses dari http://www.academia.edu/5483378 URNAL_SKRIPSI

Bernardin, John H., dan Russel, Joyce E.A.(2008), Human Resources Managment: An Experiential Approach, Jakarta: Gramedia Pustaka.

Cangara, Hafied (2005) Pengantar Ilmu Komunikasi, Jakarta: Radja Grafindo Persada.

Dede, Hasan (2012), Pengaruh Komunikasi Organisasi Terhadap Kinerja Pegawai Pada Dinas Pendidikan Provinsi Jawa Barat: Jurnal Universitas Pasundan

Effendy, Onong Uchjana (2009), Ilmu Teori dan Filsafat Komunikasi. Bandung: Remaja Rosdakarya.

Gayatri, G., Imbaruddin, A., \& Muttaqin, M. (2018). Analysis of Employee Performance in PT. Bank Mandiri (Persero), Tbk. Cendrawasih Makassar Branch. Jurnal Administrasi Negara, 24(3), 189-199. https://doi.org/10.33509/jan.v24i3.39 
Hakim, Rahmat Budi (2014), Manajemen dan Evaluasi Kinerja Karyawan, edisi pertama, cetakan pertama, Jakarta: Aswaja Pressindo.

Masana, Sembiring (2012), Budaya Kinerja Organisasi, (Perspektif Organisasi Pemerintah), Bandung: Fokus Media.

Noor Juliansyah (2014), Analisis Data Penelitian Ekonomi dan Manajemen, Jakarta: Kompas Gramedia.

Pace, R. Wayne dan Faules, Don F (2005)

Komunikasi Organisasi, Bandung: PT. Remaja Rosdakarya.

Pratminingsih, S.A \& Rudatin, C.L and Rimenta, T (2014), Roles of Motivation and Destination Image in Predicting Tourist Revisit Intention: A Case of Bandung - Indonesia. Diakses dari http://www.ijimt.org/ papers/479S10005.pdf

Rachmawati, Ike Kusdyah (2008), Manajemen Sumber Daya Manusia, edisi pertama, cetakan ketujuh, Yogyakarta: Andi.

Rakhmat, J.( 2008), Metode Penelitian Komunikasi. Bandung: Remaja Rosdakarya.

Rasyid, Nuraini (2018), Pengaruh Budaya Organisasi dan Motivasi Karyawan Terhadap Kinerja Karyawan Pada PT. Dunia Marine Products di Makassar. Jurnal BISNIS \& KEWIRAUSAHAAN Vol 7(1) diakses dari https://e-jurnal.stienobel indonesia.ac.id/index.php/jbk/articl /view/163

Rivai, Veithzal dan Jauvani Sagala (2008), Manajemen Sumber Daya Manusia untuk Perusahaan Dari Teori ke Praktik, Edisi Revisi, Jakarta: PT. Raja Grafindo Persada.

Romli, Komsahrial (2011), Komunikasi Organisasi Lengkap, Jakarta: Grasindo.
Sinambella, Poltak Lijan (2012), Kinerja Pegawai Teori Pengukuran dan Implikasi, edisi pertama, cetakan pertama, Jakarta: Graha Ilmu.

Sugiyono (2010), Statistik Untuk Penelitian, cetkan kesembilanbelas, Bandung: Alfabeta.

Waluyo dan Hermawan (2019), Pengaruh gaya komunikasi organisasi terhadap prestasi kerja pegawai pada Biro Komunikasi Layanan Masyarakat Kemendikbud Jakarta. Vol. 6 (2) (169-178), DOI: 10.32493/skr.v6i2. $\underline{5537}$

Wibowo (2014), Perilaku Dalam Organisasi, edisi pertama, cetakan kedua, Jakarta: Raja Grafindo Persada.

Wijayanto, Dian (2012), Pengantar Manajemen, Jakarta: Gramedia Pustaka Utama.

Tafjiyra N Ainan (2015), Pengaruh Penerapan Pola Komunikasi Organisasi Terhadap Kinerja Pegawai Di Dinas Kebudayaan Dan Pariwisata Provinsi Sulawesi Selatan. Doctoral Dissertation, UNIVERSITAS HASANUDDIN Diakses dari http://repository. unhas.ac.id/handle/23456789/15492 